Corrigendum

\title{
Corrigendum to "Field Pea (Pisum sativum L.) Variety Development for Moisture Deficit Areas of Eastern Amhara, Ethiopia"
}

\author{
Yirga Kindie ${ }^{(D)}{ }^{1}$ Aemiro Bezabih, ${ }^{2}$ Wubeshet Beshir, ${ }^{1}$ Zinabu Nigusie, ${ }^{1}$ \\ Zelalem Asemamaw, ${ }^{1}$ Antenh Ademe, ${ }^{3}$ Birke Tebabele, ${ }^{1}$ Genet Kebede, ${ }^{1}$ \\ Tesfay Alemayehu, ${ }^{1}$ and Fentaw Assres ${ }^{1}$
}

${ }^{1}$ Sekota Dryland Agricultural Research Center, P.O. Box 62, Sekota, Ethiopia

${ }^{2}$ Debre Birhan Agricultural Research Center, P.O. Box 112, Debre Birhan, Ethiopia

${ }^{3}$ Adet Agricultural Research Center, P.O. Box 8, Bahir Dar, Ethiopia

Correspondence should be addressed to Yirga Kindie; ykindie2007@gmail.com

Received 30 May 2019; Accepted 3 June 2019; Published 13 October 2019

Copyright (C) 2019 Yirga Kindie et al. This is an open access article distributed under the Creative Commons Attribution License, which permits unrestricted use, distribution, and reproduction in any medium, provided the original work is properly cited.

In the article titled "Field Pea (Pisum sativum L.) Variety Development for Moisture Deficit Areas of Eastern Amhara, Ethiopia" [1], there was a spelling error in the name format of Mr. Antenh Ademe as it was written as Antenh Adem. The corrected name format is shown above.

\section{References}

[1] Y. Kindie, A. Bezabih, W. Beshir et al., "Field pea (Pisum sativum L.) variety development for moisture deficit areas of eastern amhara, Ethiopia," Advances in Agriculture, vol. 2019, Article ID 1398612, 6 pages, 2019. 


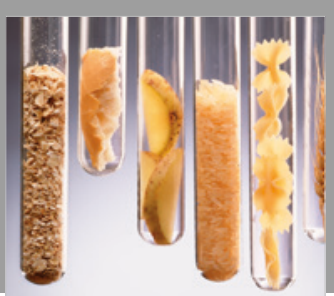

International Journal of Food Science

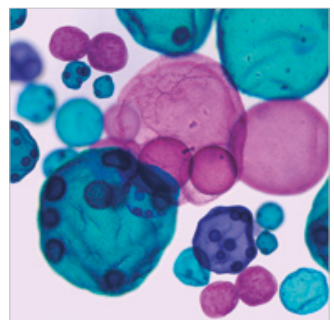

International Journal of Microbiology
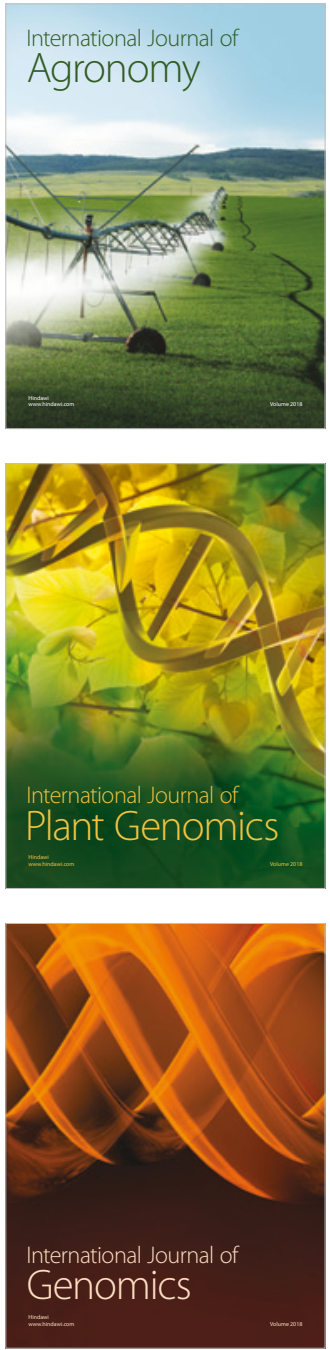

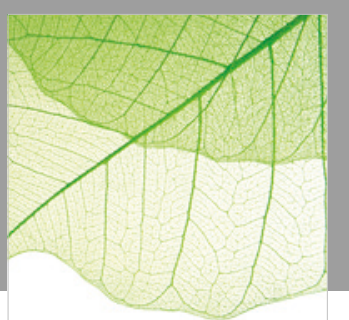

Journal of Botany
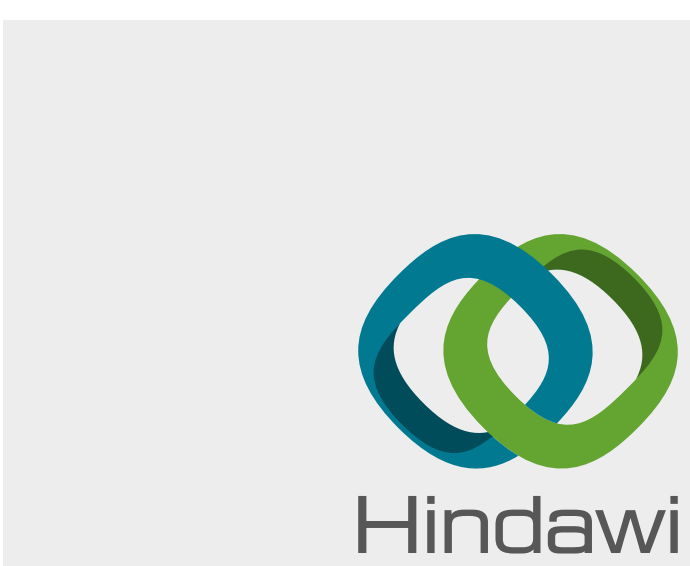

Submit your manuscripts at

www.hindawi.com
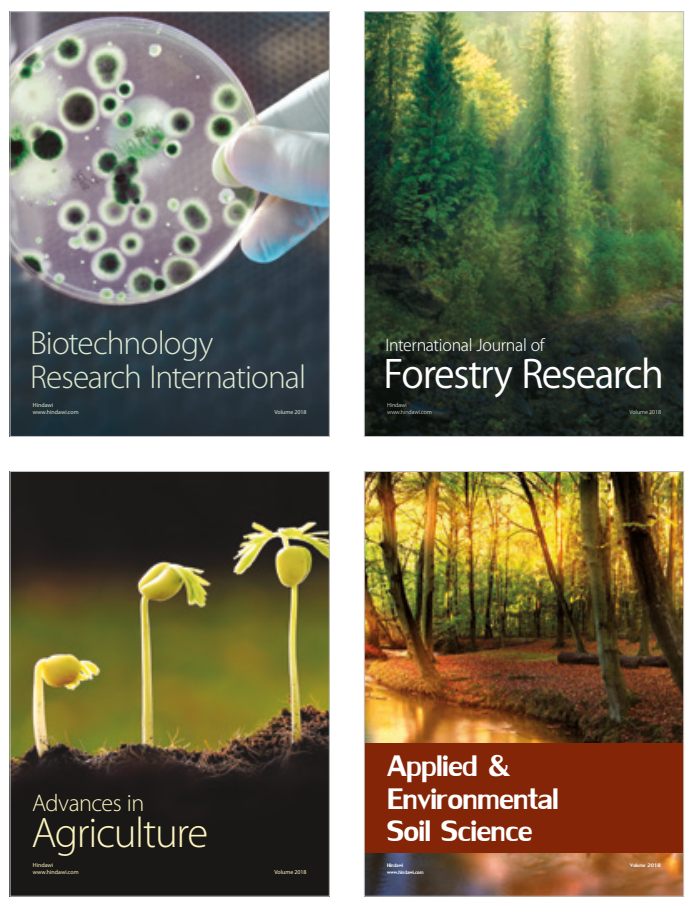

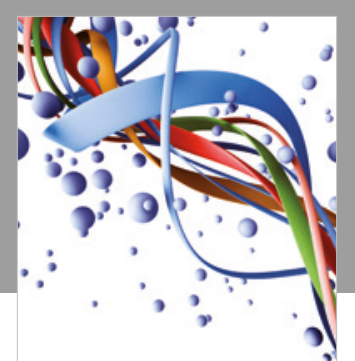

Scientifica

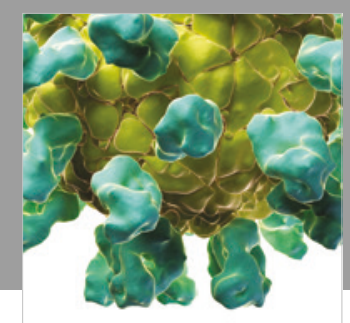

Veterinary Medicine International

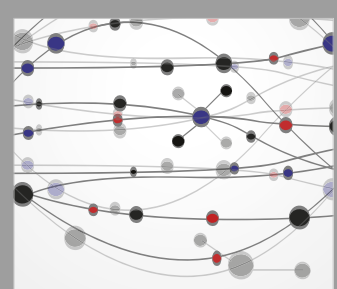

The Scientific World Journal
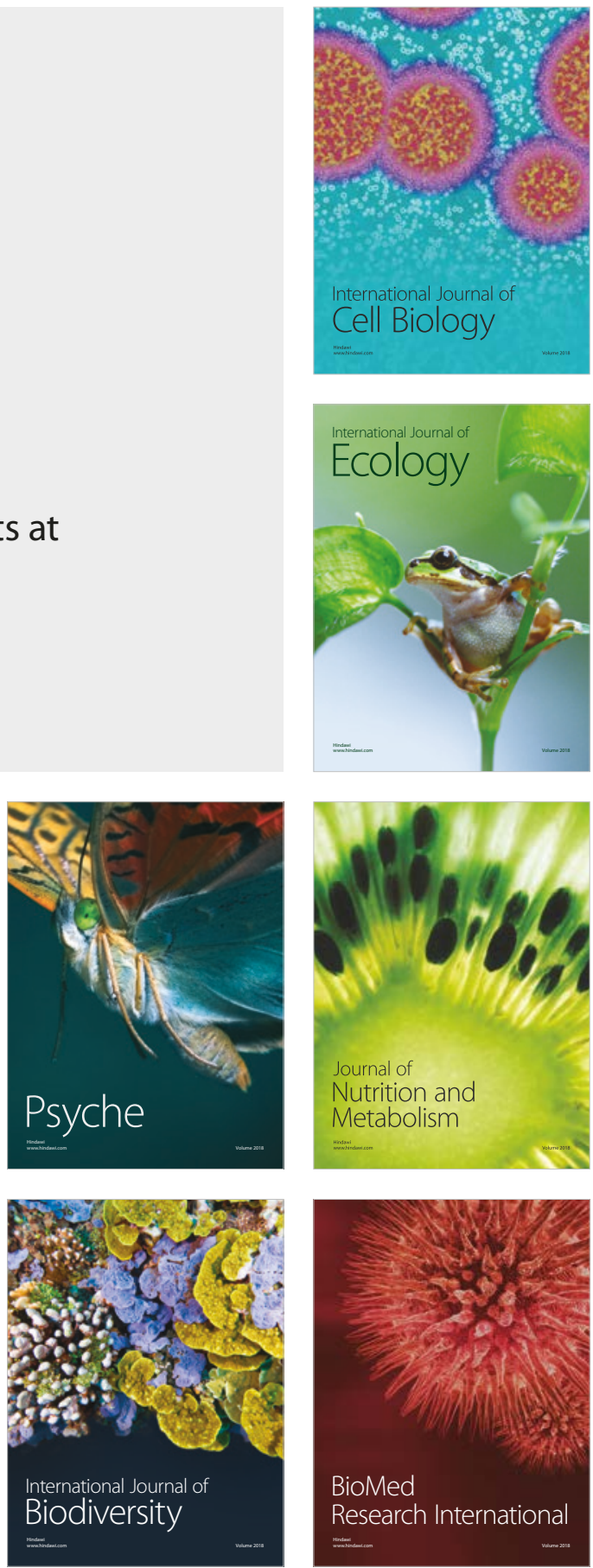